\title{
ESTIMATIVA DA PRODUÇÃO DE BIOGÁS EM ATERRO SANITÁRIO SUBTROPICAL BRASILEIRO
}

\author{
Maria Isabel Coltro Crovador* \\ Waldir Nagel Schirmer** \\ Kelly Geronazzo Martins*** \\ Rafaela Franqueto**** \\ José Fernando Thomé Jucá ${ }^{* * * * *}$
}

RESUMO: O presente estudo teve como objetivo avaliar o potencial de geração de biogás de aterro sanitário sob duas abordagens utilizando um modelo de primeira ordem: abordagem prática, utilizando parâmetros calculados experimentalmente a partir de biodigestores em laboratório; e teórica, com valores-padrão (default). Os resultados mostraram que o total acumulado num cenário de 2008 a 2148 foi de 42.877 toneladas de biogás ou, ainda $11.453 \mathrm{t}$ de metano (abordagem prática), e de 148.062 t de biogás ou 39.549 t de metano (abordagem teórica). Já o pico da geração de biogás ocorreria da mesma forma em ambas as abordagens, em 2020. A aplicação do modelo revelou que, teoricamente, a produção de biogás pode ser três vezes maior do que os resultados práticos e o período real das maiores taxas de geração podem ser bem mais curtos do que o previsto quando são utilizados parâmetros default. Isso denota que a base de dados internacional pode não ser adequada à realidade dos aterros do Brasil.

PALAVRAS-CHAVE: Aproveitamento de biogás; LandGem; Resíduos sólidos urbanos.

\section{PRODUCTION ESTIMATES OF BIOGAS IN A BRAZILIAN SUBTROPICAL SANITARY LANDFILL}

ABSTRACT: Biogas generation capacity from a sanitary landfill is investigated by two approaches with two first order models: practical approach with experimentally

\footnotetext{
Centro Estadual Florestal de Educação Profissional Presidente Costa e Silva. Mestre em Bioenergia pela UNICENTRO, Brasil.

** Docente Associado do curso de Engenharia Ambiental e Mestrado em Bioenergia da UNICENTRO; Doutor em Engenharia Ambiental pela UFSC, Brasil. E-mail: wanasch@hotmail.com

*** UNICENTRO; Doutora em Engenharia Florestal pela Universidade Federal do Paraná (UFPR), Brasil

***** Fundação Universidade Regional de Blumenau (FURB); Mestre em Engenharia Sanitária e Ambiental pela UNICENTRO, Brasil.

${ }^{* * * * *}$ Docente Titular do Departamento de Engenharia Civil da Universidade Federal de Pernambuco (UFPE); Doutor em Geotecnia pela Universidad Politécnica de Madrid, Espanha.
} 
calculated parameters from laboratory biodigestors; a theoretical approach with defaults. Results showed that accumulated total between 2008 and 2148 reached 42,877 tons of biogas or 11,453 tons of methane, and 148,062 ton of biogas or 39,549 tons of methane, by the theoretical approach. Highest rate of biogas production would be the same in the two approaches by 2020 . The model revealed that theoretically biogas production may be three times greater than practical results and the real period of higher generation rates would be shorter than forecasted when default parameters were employed. The above means that international data may not be applicable to the true situation of landfills in Brazil

KEY WORDS: Use of biogas; LandGem; Urban solid wastes.

\section{INTRODUÇÃO}

A disposição em aterros sanitários é o método mais utilizado para o tratamento e destinação final de resíduos sólidos municipais (STAUB et al., 2011) por apresentar menor custo e maior minimização dos impactos ambientais, quando comparada a outras formas de tratamento, como incineração e compostagem.

Pelo potencial combustível do metano, a recuperação do biogás, gerado em aterros sanitários (landfill gas - LFG) para fins energéticos, constitui-se em uma opção que pode ser interessante economicamente e que vem ao encontro da crescente demanda por combustíveis renováveis e da preocupação internacional com a sustentabilidade. Segundo Rasi, Läntelä e Rintala (2011), o biogás pode tanto ser utilizado no local onde é produzido como pode ser distribuído por redes de distribuição de gás. Independentemente do seu uso, porém, é fundamental conhecer o potencial de geração desse gás em cada aterro.

No caso específico do Brasil, a expectativa é de um aumento na quantidade de aterros sanitários com condições de captação de biogás para uso energético. Isso se deve à promulgação da lei federal $n^{0} 12.305 / 2010$, regulamentada pelo decreto federal $n^{0} 7.404 / 2010$, que instituiu a nova Política Nacional de Resíduos Sólidos (PNRS) no país (BRASIL, 2010).

Portanto, ressalta-se que estudos que abordem a determinação do potencial de geração de biogás, a partir de RSU, são fundamentais para o estabelecimento 
de programas de recuperação energética do gás gerado em aterros sanitários, uma vez que tais estudos fornecem informações importantes à avaliação de viabilidade técnica e econômico-financeira. Deve-se considerar ainda a sustentabilidade no uso dessa energia, de forma que represente uma alternativa viável não só do ponto de vista econômico, mas de preservação ao meio ambiente e à saúde das populações vizinhas e dos trabalhadores dos aterros sanitários.

Modelos para estimar a produção de metano em aterros são ferramentas úteis para projetar essas emissões ao longo do tempo e podem ser usados para dimensionar sistemas de coleta de biogás, avaliações e projeções de recuperação de energia e para regulamentações de emissões. Em comparação com outros métodos (a exemplo de métodos de campo), os modelos teóricos apresentam vantagens, tais como o baixo custo e resultados rapidamente observáveis (VOGT; AUGENSTEIN, 1997). Neste contexto, o presente estudo teve como objetivo principal operacionalizar o modelo de primeira ordem Scholl Canyon (LandGEM) mediante uma abordagem teórica, usando valores padrão para os parâmetros $k$ e $L_{0}$, sugeridos pela literatura, e uma abordagem prática, com os parâmetros $k$ e $L_{0}$ obtidos experimentalmente a partir da biodigestão da fração orgânica de resíduo sólido urbano. As curvas obtidas nessas duas abordagens foram comparadas em termos de geração de biogás.

\section{MATERIAL E MÉTODOS}

\subsection{CARACTERÍSTICAS DO LOCAL DE ESTUDO E DOS RESÍDUOS UTILIZADOS}

As amostras de RSU utilizadas foram coletadas num aterro sanitário do Estado do Paraná, região Sul do Brasil. O clima dessa região é temperado, com temperatura média no mês mais frio abaixo de $18^{\circ} \mathrm{C}$, com verões frescos, temperatura média no mês mais quente abaixo de $22^{\circ} \mathrm{C}$ e sem estação seca definida (IAPAR,1998).

Para a determinação do potencial de geração do biogás $\left(L_{0}\right)$, foi coletada uma amostra de resíduo orgânico fresco do dia anterior, ainda não aterrado. $\mathrm{O}$ parâmetro $L_{0}$ foi calculado mediante os resultados de geração máxima de metano nos ensaios com o resíduo orgânico fresco. Foi utilizado como percentual de 
composição de metano no biogás o valor de $50 \%$, sugerido pelo LandGEM.

Para a determinação da constante da taxa de geração de metano $(k)$, foi coletada uma amostra de resíduos orgânicos com 2,5 anos de idade (tempo de aterramento). Justifica-se a utilização do resíduo de 2,5 anos para determinação do valor de $k$ pelo fato de que este parâmetro depende do período de degradação do resíduo dentro da célula, fator que só pode ser estimado com o estudo das condições de resíduos já confinados há um tempo mínimo necessário para degradação da matéria orgânica (considerando que este estudo se concentra nas características desta parcela dos RSU). Foram descartados materiais tais como metais, plásticos, tecidos, papéis, madeira, vidro e outros de difícil degradação. A partir das pilhas formadas, as amostras de resíduos foram obtidas por quarteamento, conforme a norma ABNT NBR 10.007 de 2004 (ABNT, 2004), resultando na seleção de aproximadamente 1,50 $\mathrm{kg}$ de cada amostra inicial (resíduo orgânico fresco e resíduo orgânico de 2,5 anos).

Em laboratório, as amostras foram secas em estufa a $60^{\circ} \mathrm{C}$ até obtenção de massa constante. Para garantir a homogeneidade das amostras, os resíduos secos foram triturados em um moinho de martelo do tipo Willey. A caracterização granulométrica de ambos os resíduos deu-se por meio do peneiramento do resíduo em peneiras da série Tyler, com malha de 9 a 270.

O inóculo utilizado nos biodigestores foi o lodo de reator RALF (reator anaeróbio de leito fluidificado), coletado na estação de tratamento de esgotos local. O lodo foi coletado e caracterizado no mesmo dia em que os biodigestores foram preparados e tiveram partida.

\subsection{PARTIDA DOS BIODIGESTORES ANAERÓBIOS DE BANCADA}

A etapa experimental consistiu na montagem e monitoramento de biodigestores anaeróbios de bancada, próprios à verificação do potencial de geração de biogás. Cada biodigestor consistiu de um frasco de borossilicato de $250 \mathrm{~mL}$, com tampa equipada com uma válvula de saída de gás e manômetro para monitoramento da pressão interna. Os valores de pressão foram convertidos em volume de biogás nas condições normais de temperatura e pressão (CNTP) de acordo com a lei de gases ideais $(\mathrm{PV}=\mathrm{nRT})$, em que: P: pressão absoluta medida nos manômetros; V: volume de biogás gerado; T: temperatura do biogás; R: constante universal dos gases 
(LABATUT; ANGENENT; SCOTT, 2011).

A parte experimental compreendeu os seguintes tratamentos:

a) Tratamento 1: substrato de resíduo fresco (nos biodigestores aqui denominados de S1, S2, S3, S4, S5 e S6), cada um com 2,0 g do resíduo fresco seco e moído inoculado com $100 \mathrm{~mL}$ de lodo;

b) Tratamento 2: substrato de resíduo com dois anos e meio de aterramento (com triplicata de biodigestores mantendo-se a mesma proporção de inóculo e resíduo utilizada no Tratamento 1 - 1:50) (SCHIRMER et al., 2014).

c) Tratamento 3: inóculo (aqui denominados I1, I2, I3, I4), que foram os biodigestores de controle (brancos), cada um composto por apenas 100 $\mathrm{mL}$ de lodo. Como os três tratamentos foram simultâneos, os brancos serviram tanto para o Tratamento 1 quanto para o 2.

Em todos os ensaios, uma corrente de gás nitrogênio foi circulada no headspace de cada biodigestor por cerca de 05 minutos, de modo a garantir a anaerobiose do meio (MSHANDETE et al., 2004). Em seguida, os biodigestores foram incubados em estufa bacteriológica a uma temperatura constante e igual a $35^{\circ} \mathrm{C}$ (LABATUT; ANGENENT; SCOTT, 2011; SCHIRMER et al., 2014), em que permaneceram por um período de 91 dias. A produção líquida de biogás foi obtida subtraindo a produção dos biodigestores de controle (brancos) da produção dos biodigestores com resíduo.

\subsection{CARACTERIZAÇÃO FÍSICO-QUÍMICA DAS AMOSTRAS}

Testes preliminares com o resíduo de 2,5 anos indicaram um potencial de geração de biogás praticamente nulo (em todas as suas repetições). Por este motivo, foi feita a caracterização físico-química apenas do resíduo fresco (Tratamento 1) e do inóculo (Tratamento 3), com o objetivo de compreender a evolução das características físico-químicas das amostras durante o processo de biodegradação e geração de biogás, o que efetivamente só ocorreu com o resíduo fresco. As análises físico-químicas para caracterização inicial e final (após 91 dias de incubação) das 
amostras deram-se conforme o Standard Methods for the Examination of Water and Wastewater (APHA, 1998). Os seguintes parâmetros foram monitorados: umidade, $\mathrm{pH}$, alcalinidade, ácidos voláteis, demanda bioquímica de oxigênio $\left(\mathrm{DBO}_{5}\right)$, demanda química de oxigênio (DQO), sólidos totais (ST), sólidos totais fixos (STF) e sólidos totais voláteis (STV).

\subsection{MODELAGEM DO POTENCIAL TEÓRICO DE GERAÇÃO DE BIOGÁS}

De modo a relacionar os dados experimentais obtidos em laboratório aos modelos teóricos de previsão de produção de biogás em aterros sanitários, os resultados obtidos no ensaio de bancada com os biodigestores anaeróbios foram aplicados no cálculo dos parâmetros $k$ (expressa em ano $\left.{ }^{-1}\right)$ e $L_{0}\left(\mathrm{em} \mathrm{m}^{3} \cdot \mathrm{t}_{\mathrm{RSU}}{ }^{-1}\right)$. Foi selecionado, então, um modelo teórico para estimar as emissões de metano no aterro avaliado, inserindo valores práticos (ensaio de bancada) e valores default (padrões, obtidos na literatura), com o objetivo de realizar comparações entre as curvas de geração obtidas para cada caso.

O modelo escolhido para ser aplicado a este trabalho foi o Scholl-Canyon, modelo de primeira ordem (Equação 1) usado por indústrias e agências reguladoras, tais como a USEPA, a qual o utiliza em sua versão de computador o Landfill Gas Emissions Model (LandGEM) (BANCO MUNDIAL, 2004):

$Q_{\mathrm{CH}_{4} \mathrm{i}}=k \times L_{0} \times m_{i} \times e^{-k t}$

em que: $\mathrm{Q}_{\mathrm{CH} 4 \mathrm{i}}=$ metano produzido no ano "i"; $\mathrm{k}=$ constante de geração de metano; $\mathrm{L}_{0}=$ potencial de geração de metano; $\mathrm{m}_{\mathrm{i}}=$ resíduos depositados no ano "i"; $\mathrm{t}=$ anos após o fechamento do aterro.

O valor teórico do potencial de geração de metano $\left(L_{0}\right)$ depende apenas do tipo de resíduo USEPA (1991) e USEPA (2005), sendo $170 \mathrm{~m}^{3}$ o parâmetro default (USEPA, 2005). O valor de $k$ estabelece a taxa de geração de metano para os RSU no aterro, sendo função das seguintes variáveis: teor de umidade dos resíduos,

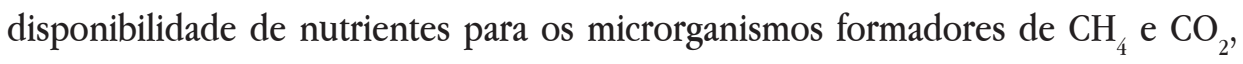


pH e temperatura dos resíduos. O valor default de $k$ é de 0,05 ano $^{-1}$ (USEPA, 2005).

$\mathrm{O}$ LandGEM permite estimar as emissões de $\mathrm{CH}_{4}, \mathrm{CO}_{2}$, compostos orgânicos não metanados (NMOC) e poluentes perigosos a partir de aterros de RSU, pautado em uma equação de decaimento de primeira ordem. Os inputs podem ser específicos do local em estudo ou, caso não existam dados disponíveis, parâmetros default podem ser utilizados ABRELPE e MGM INNOVA (2013). O LandGem foi utilizado sob duas abordagens: abordagem prática: operacionalização do modelo com inserção de parâmetros obtidos no experimento de bancada $\left(k\right.$ e $\left.L_{0}\right)$; abordagem teórica: operacionalização do modelo com inserção de parâmetros padrão (default).

\subsubsection{Abordagem prática: cálculo e seleção das variáveis}

As variáveis utilizadas para operacionalizar o modelo foram obtidas da seguinte forma: $\mathrm{Q}_{\mathrm{CH} \text { 4i }}$ quantidade de biogás; $\mathrm{k}$ : valor calculado a partir dos dados do experimento de bancada; $\mathrm{L}_{0}$ : valor calculado a partir dos dados do experimento de bancada; $m_{i}$ : quantidade de resíduos aterrados ao ano. Foi utilizado dado real de volume de RSU produzido referente ao ano de 2007 , fornecido pela prefeitura do município que gerencia o aterro, a partir do qual foi feita a estimativa de quantidades aterradas por 80 anos, considerando uma taxa de crescimento da população atendida e da respectiva quantidade de RSU de $0,87 \%$ ano ${ }^{-1}$ (taxa média geométrica de crescimento anual da população - população presente e residente, ano 2010, referente à região Sul do Brasil) (IBGE, 2010); t: anos após o fechamento do aterro. Foi utilizado um período de 80 anos para a estimativa de produção de RSU, conforme o limite de inputs do modelo, considerando ainda que a vida útil do aterro é de 11 anos (de 2008 a 2019) para a aceitação de resíduos. A estimativa de produção de biogás compreendeu o período de 2008 a 2148 (conforme formatação própria do modelo). Esse critério também foi adotado para a abordagem teórica.

Com os resultados do ensaio e características do resíduo orgânico de 2,5 anos, estimou-se o valor de t (tempo) e, portanto, a constante de geração de biogás $(k)$, já que $k=\mathrm{t}^{-1}$.

\subsubsection{Abordagem teórica: cálculo e seleção das variáveis}

As variáveis utilizadas para operacionalizar o modelo foram obtidas da 
seguinte forma: $\mathrm{Q}_{\mathrm{CH} 4 \mathrm{i}}$ : quantidade de biogás; $\mathrm{k}$ : valor padrão (default); $\mathrm{L}_{0}$ : valor padrão (default); $\mathrm{m}_{\mathrm{i}}$ : quantidade de resíduos aterrados ao ano, por 80 anos (o mesmo procedimento descrito na abordagem prática); t: anos após o fechamento do aterro.

\subsubsection{Comparação entre as curvas de geração: abordagem prática $\times$ aborda- gem teórica}

Com o valor de biogás gerado pelas duas abordagens, foram obtidas as curvas de geração de biogás ao longo dos anos de 2008 a 2148. Embora na abordagem prática os parâmetros $k$ e $L_{0}$ se refiram à fração orgânica, foi utilizada a mesma quantidade de resíduos (valor total, orgânicos e não orgânicos) nas duas abordagens, a fim de possibilitar comparações.

\section{RESULTADOS E DISCUSSÃO}

\subsection{ENSAIOS COM BIODIGESTORES ANAERÓBIOS DE BANCADA}

\subsubsection{Caracterização físico-química das amostras (substrato e inóculo)}

Nesse caso, foi obtida a seguinte classificação, em percentual de massa retida nas peneiras de quatro diferentes faixas granulométricas: $0 \%$ Mesh/Tyler 9 (2 mm); 19,56 \% Mesh/Tyler 18 (1 mm); 60,41 \% Mesh/Tyler 65 (0,212 mm); 20,03 \% Mesh/Tyler $270(0,053 \mathrm{~mm})$. Assim, 80,44\% do resíduo utilizado pertenciam à faixa granulométrica menor do que $0,212 \mathrm{~mm}$.

Na Tabela 1 são apresentados os resultados (valores médios) da caracterização físico-química inicial e final após 91 dias de incubação do substrato (Tratamento 1) e inóculo (Tratamento 3). Todos os parâmetros foram determinados em triplicata. 
Tabela 1. Caracterização físico-química inicial e final dos Tratamentos 1 e 3

\begin{tabular}{|c|c|c|c|c|c|}
\hline \multirow{2}{*}{ Parâmetros } & \multicolumn{3}{|c|}{ Caracterização do tratamento 1} & \multicolumn{2}{|c|}{$\begin{array}{c}\text { Caracterização do tratamento } \\
3\end{array}$} \\
\hline & $\begin{array}{l}\text { Inicial } \\
\text { (Dia 0) }\end{array}$ & $\begin{array}{l}\text { Parcial } \\
\text { (Dia 8) }\end{array}$ & $\begin{array}{c}\text { Final } \\
\text { (Dia 91) }\end{array}$ & $\begin{array}{l}\text { Inicial } \\
\text { (Dia 0) }\end{array}$ & $\begin{array}{c}\text { Final } \\
\text { (Dia 91) }\end{array}$ \\
\hline Umidade (\%) & $\begin{array}{c}94,23 \pm \\
0,11\end{array}$ & - & $\begin{array}{c}95,78 \pm \\
0,02\end{array}$ & $\begin{array}{c}95,73 \pm \\
0,06\end{array}$ & $\begin{array}{c}96,60 \pm \\
0,05\end{array}$ \\
\hline ST (mg.L $\left.L^{-1}\right)$ & $\begin{array}{c}57.891 \pm \\
1020,53\end{array}$ & - & $\begin{array}{c}41.438 \pm \\
202,57\end{array}$ & $\begin{array}{c}42.281 \pm \\
691,60\end{array}$ & $\begin{array}{c}34.445 \pm \\
691,60\end{array}$ \\
\hline STV $\left(m g . L^{-1}\right)$ & $\begin{array}{c}37.509 \pm \\
54,81\end{array}$ & - & $\begin{array}{c}22.803 \pm \\
172,14\end{array}$ & $\begin{array}{c}21.753 \pm \\
530,02\end{array}$ & $\begin{array}{c}15.240 \pm \\
445,06\end{array}$ \\
\hline STF (mg.L.$\left.^{-1}\right)$ & $\begin{array}{c}20.381 \pm \\
382,28\end{array}$ & - & $\begin{array}{c}18.635 \pm \\
191,57\end{array}$ & $\begin{array}{c}20.528 \pm \\
210,43\end{array}$ & $\begin{array}{c}19.205 \pm \\
247,13\end{array}$ \\
\hline DQO (mg. $\left.\mathrm{L}^{-1}\right)$ & $\begin{array}{c}34.467 \pm \\
6211,55\end{array}$ & - & $\begin{array}{c}41.233 \pm \\
2353,90\end{array}$ & $\begin{array}{r}20.433 \pm \\
4986,32\end{array}$ & $\begin{array}{c}22.433 \pm \\
1241,30\end{array}$ \\
\hline $\mathrm{DBO}_{5}$ & $\begin{array}{l}7.463 \pm \\
229,81\end{array}$ & - & $\begin{array}{c}6.130 \pm \\
28,28\end{array}$ & $\begin{array}{c}3.168 \pm \\
272,24\end{array}$ & $\begin{array}{l}845 \pm \\
84,85\end{array}$ \\
\hline $\mathrm{pH}\left(\mathrm{mg} \cdot \mathrm{L}^{-1}\right)$ & $\begin{array}{c}6,14 \pm \\
0,14\end{array}$ & $\begin{array}{c}4,95 \pm \\
0,01\end{array}$ & $\begin{array}{c}6,59 \pm \\
0,07\end{array}$ & $\begin{array}{c}6,62 \pm \\
0,03\end{array}$ & $\begin{array}{c}7,31 \pm \\
0,03\end{array}$ \\
\hline $\begin{array}{l}\text { Alcalinidade } \\
\text { total }\left(\mathrm{mg} \cdot \mathrm{L}^{-1}\right)\end{array}$ & $\begin{array}{c}593 \pm \\
0,00\end{array}$ & $\begin{array}{l}612 \pm \\
16,17\end{array}$ & $\begin{array}{c}2.740 \pm \\
172,04\end{array}$ & $\begin{array}{r}621 \pm \\
49,07\end{array}$ & $\begin{array}{c}2.627 \pm \\
14,00\end{array}$ \\
\hline $\begin{array}{l}\text { Ácidos voláteis } \\
\left(\mathrm{mg} . \mathrm{L}^{-1}\right)\end{array}$ & $\begin{array}{c}1.225 \pm \\
77,98\end{array}$ & $\begin{array}{c}3.562 \pm \\
126,62\end{array}$ & $\begin{array}{l}3.792 \pm \\
72,17\end{array}$ & $\begin{array}{c}1.175 \pm \\
21,94\end{array}$ & $\begin{array}{c}2.208 \pm \\
36,37\end{array}$ \\
\hline
\end{tabular}

Os valores de umidade iniciais das amostras aproximam-se da faixa apresentada por Andreoli et al. (2003) e USEPA (1991) como ideal para o processo de biodigestão (60 a 90\%). Como o resíduo utilizado foi previamente seco, toda a umidade da amostra era proveniente do inóculo (umidade inicial de 96\%). Praticamente não houve variação da umidade até o final do experimento.

$\mathrm{O}$ pH inicial do experimento, que para o Tratamento 1 era de 6,14 e para o Tratamento 3 de 6,62, ficou dentro do desejável, próximo da neutralidade, favorecendo a ação dos micro-organismos (BIDONE; POVINELLI, 1999).

Os ácidos graxos voláteis (AGV), formados durante a fase ácida da digestão anaeróbia, tendem a diminuir o pH do meio, o que leva à redução da 
atividade das bactérias metanogênicas, sensíveis a pH baixos (ZHANG et al., 2008). Por isso, a alcalinidade é de grande importância na digestão anaeróbia, pois é um parâmetro que possibilita a neutralização dos ácidos formados durante o processo e o tamponamento do $\mathrm{pH}$, na eventualidade do acúmulo de ácidos voláteis (CHERNICHARO, 1997). Piveli e Kato (2006) afirmam que nos digestores anaeróbios de lodo de esgoto é necessária uma alcalinidade de bicarbonatos elevada, situandose na faixa de 1.000 a $5.000 \mathrm{mg} . \mathrm{L}^{-1} \mathrm{em} \mathrm{CaCO}_{3}$. No presente estudo, foi observada a produção de alcalinidade durante os 91 dias de experimento, atingindo valores finais de $2.740 \mathrm{mg} . \mathrm{L}^{-1} \mathrm{e} 2.627 \mathrm{mg} . \mathrm{L}^{-1}$ para os Tratamentos 1 e 3 , respectivamente, o que fica dentro da faixa mencionada por Piveli e Kato (2006). Isso provavelmente ocorreu pela formação de sais de ácidos voláteis, já que os mesmos também aumentaram significativamente nos biodigestores dos Tratamentos 1 e 3. Essa produção de alcalinidade e ácidos voláteis indica a conversão de matéria orgânica com a produção de ácidos orgânicos a partir do material orgânico complexo, em uma reação de equilíbrio de acetato a ácido acético.

Com relação ao teor de matéria orgânica, evidenciado pela DQO inicial do Tratamento 1, de $34.467 \mathrm{mg} . \mathrm{L}^{-1}$, nota-se que apenas $22 \%$, correspondente ao valor da $\mathrm{DBO}_{5}$ de $7.463 \mathrm{mg} . \mathrm{L}^{-1}$, era biodegradável. De acordo com Von Sperling (2005), uma razão $\mathrm{DQO} / \mathrm{DBO}_{5}$ baixa, menor do que 2,5, indica uma fração biodegradável elevada, adequada para tratamento biológico. Valores maiores que 3,5 ou 4,0 denotam uma fração inerte (não biodegradável) elevada, situação mais adequada para tratamento físico-químico. A razão $\mathrm{DQO} / \mathrm{DBO}_{5}$ obtida foi considerada elevada para todas as amostras, sendo que no Tratamento 1 foi de 4,62 no início e 6,73 ao final do ensaio. Já para o Tratamento 3, essa relação foi de 6,45 no início do experimento e 26,55 no final. O aumento dos valores após o tempo de incubação se deve ao consumo da matéria orgânica biodegradável, evidenciada pela $\mathrm{DBO}_{5}$. Esses resultados mostram que o inóculo não apresentava as melhores condições para propiciar a degradação biológica, o que pode ter afetado o volume final de biogás obtido.

$\mathrm{A} \mathrm{DBO}_{5}$ teve uma redução de $18 \%$ no substrato e $73 \%$ no inóculo, o que demonstra que o consumo da matéria-orgânica biodegradável foi mais intenso nos biodigestores de controle (brancos) do que nos biodigestores contendo resíduo. Isso pode ser justificado pela adaptação das bactérias ao ambiente já que, por conter apenas o lodo, sem adição de resíduo, as condições estabelecidas nos biodigestores 
eram similares àquelas inerentes ao reator de onde foi coletado, o que facilitou o processo de degradação. Por outro lado, nos biodigestores contendo substrato (Tratamento 1), com a inserção de um material externo (resíduo) às condições originais em que as bactérias estavam se desenvolvendo (presença de apenas o lodo), pode ter motivado a necessidade de maior tempo de adaptação das bactérias ao meio. $\mathrm{O}$ consumo da $\mathrm{DBO}_{5}$ indica a conversão anaeróbia da matéria orgânica carbonácea, em que, conforme Von Sperling (1996), uma parte da matéria orgânica é convertida a uma forma mais oxidada (produção de $\mathrm{CO}_{2}$ ) e em outra forma mais reduzida (produção de $\mathrm{CH}_{4}$ ), sendo que a maior parte do metano é desprendida para a fase gasosa, o que resulta na efetiva remoção da matéria orgânica.

A porcentagem de sólidos totais voláteis (STV) no total de matéria sólida do Tratamento 1 era inicialmente 65\%, chegando a 55\% no final do experimento (base seca). Já o percentual de STV do Tratamento 3 foi de $51 \%$ a $44 \%$ durante o período de degradação. De acordo com Decottignies et al. (2005), um resíduo pode ser considerado estabilizado na faixa de sólidos voláteis de 10 a 17,4\%; já, segundo Kelly (2002), amostras podem ser consideradas estabilizadas quando as concentrações de sólidos voláteis são menores que $20 \%$ (já que contêm pouco material degradável), portanto, bem abaixo dos valores finais observados nesse trabalho após os 91 dias de digestão. Ao longo desse período de incubação, observaram-se percentuais de redução de 39\% e 30\% para os Tratamentos 1 e 3, respectivamente, indicando um potencial remanescente de sólidos voláteis no substrato (55\%) passíveis de degradação e geração de biogás.

A dificuldade de estabelecer uma relação direta entre as características físico-químicas das amostras e os respectivos resultados do potencial bioquímico de metano é ressaltada por Maciel (2009); isso porque existem outros fatores intervenientes no processo e que não foram controlados, a exemplo dos nutrientes presentes e das características da população microbiana (relativas ao resíduo e ao inóculo utilizados).

\subsubsection{Geração de biogás: resultados quantitativos}

A taxa de produção máxima diária de biogás foi atingida nos primeiros dias de monitoramento, conforme pode ser visto na Figura 1, que apresenta a taxa de 
produção diária para os dois tratamentos: Tratamento 1 (resíduo fresco inoculado) e Tratamento 3 (branco).

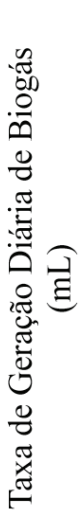

Taxa de Geração Diária de Biogás (mL/dia)

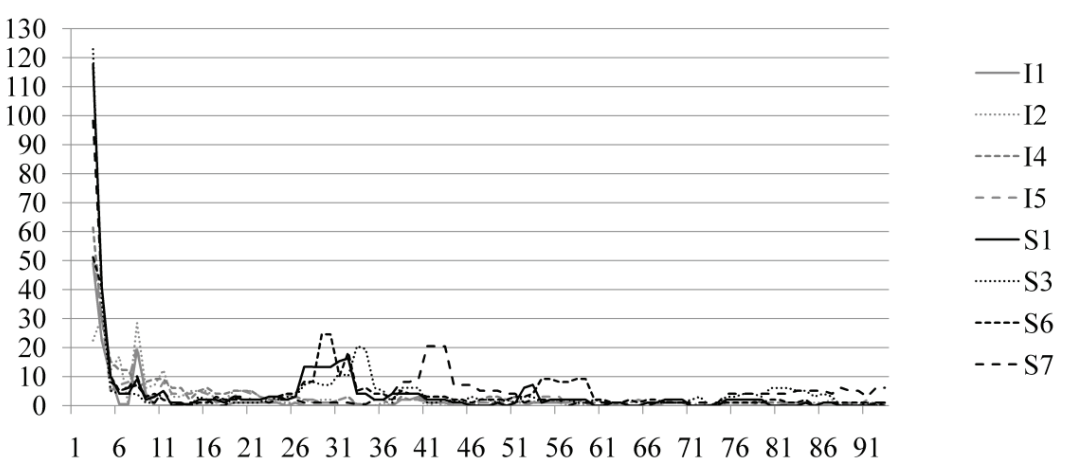

Tempo (dias)

Figura 1. Taxa de geração diária de biogás para os Tratamentos 1 e 3

Para o Tratamento 1, a taxa máxima de produção diária média de biogás foi igual a 97,56 mL.dia ${ }^{-1}$. Subtraindo a geração média dos biodigestores de controle (brancos), tem-se uma taxa máxima de produção diária média de biogás atribuída ao resíduo de 49,45 mL.dia ${ }^{-1}$.

Segundo Von Sperling (1996), quanto maior a quantidade de DBO remanescente no meio, mais rapidamente se processa a taxa de estabilização (ou biodegradação). Após algum tempo, em que a concentração da DBO já se encontra reduzida (pois parte foi estabilizada), a taxa de diminuição da DBO restante e geração de metano serão menores, pela menor concentração de matéria orgânica no meio. Isso explica o pico de geração de biogás e consequente remoção da matéria orgânica em forma de metano logo nos primeiros dias de incubação das amostras. Esse pico inicial de geração de biogás também pode ser explicado pela ausência de oxigênio desde o início do experimento, garantido pela circulação de nitrogênio gasoso no headspace dos biodigestores. Ainda, a alta geração de biogás no início do experimento deve-se às substâncias facilmente biodegradáveis presentes no substrato e ao grande volume de inóculo utilizado (PARAWIRA et al., 2004) proporcionalmente à quantidade de resíduo. Esse comportamento se repetiu em todos os biodigestores 
analisados. Observa-se que, após convertida a fração facilmente biodegradável, o processo seguiu em um ritmo mais lento, denotando a presença de materiais de mais difícil degradação por parte dos microrganismos.

No estudo de Hansen et al. (2004), em ensaios de potencial bioquímico de metano (abreviado BMP, em inglês), a partir de resíduos sólidos orgânicos em reatores com $10 \mathrm{~g} \mathrm{SV}, 400 \mathrm{~mL}$ de inóculo, período de incubação de 50 dias e temperatura controlada de $55^{\circ} \mathrm{C}$, a maior parte do biogás foi produzida nos primeiros dez dias de ensaio, o que também vem ao encontro dos resultados obtidos no presente trabalho. Da mesma forma, Schirmer et al. (2014) obtiveram uma curva semelhante àquela observada na Figura 1 para a taxa de produção diária de biogás, em que o pico de geração foi atingido nos primeiros cinco dias de experimento. $\mathrm{O}$ potencial de metano é definido por Hansen et al. (2004) como o máximo de metano produzido durante o experimento, o que é evidenciado pela geração acumulada do gás.

Na Figura 2 está ilustrada a geração acumulada de biogás durante os 91 dias de ensaio, para os dois tratamentos.

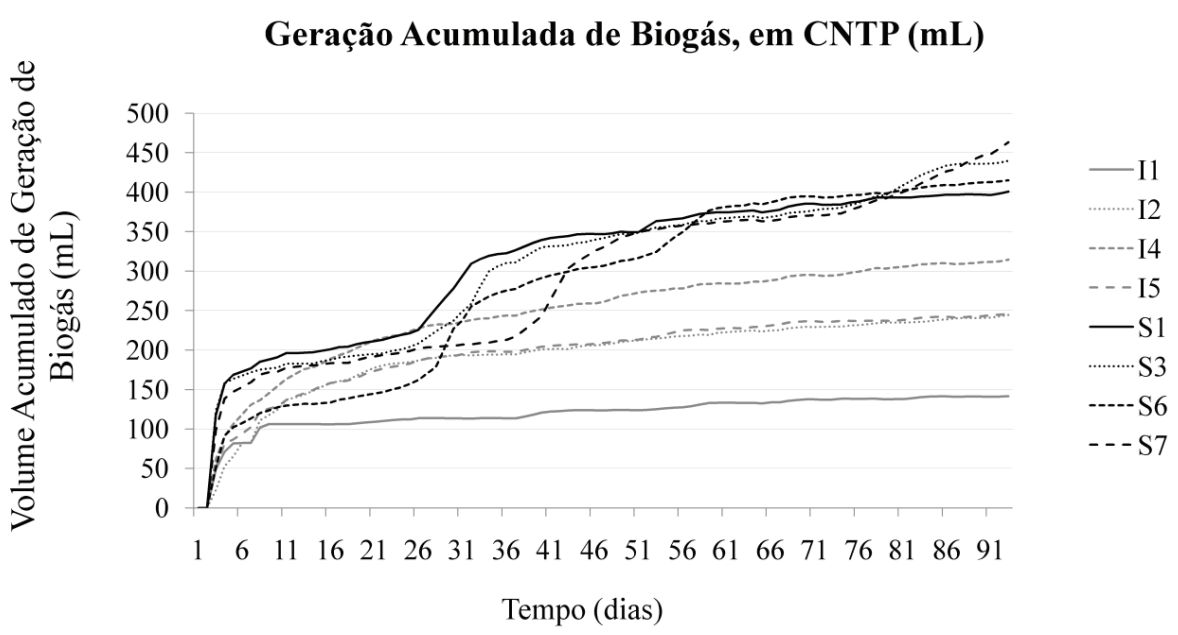

Figura 2. Geração acumulada de biogás nos Tratamentos 1 e 3

A partir do $32^{\circ}$ dia a geração de biogás referente ao substrato começa a se distanciar da produção do inóculo. Ao final do período de 91 dias, o inóculo já quase apresenta um platô, enquanto as curvas da produção do substrato ainda 
mostram tendência de crescimento. Os biodigestores com substrato alcançaram 50\% da produção total de biogás do período antes de 30 dias, exceto o biodigestor $\mathrm{S6}$, que o fez com 37 dias.

A geração de biogás do experimento de Alkanok, Demirel e Onay (2014), com resíduos orgânicos atingiu um platô com um mês de biodigestão. Schirmer et al. (2014) conduziram experimento (semelhante ao do presente trabalho) cujo platô foi atingido com aproximadamente 60 dias. Esses dois períodos são mais curtos do que o necessário para este estudo, em que com 91 dias ainda não havia um platô para a geração de biogás pelo substrato. Tal fato pode ser explicado pelo elevado percentual de sólidos voláteis totais (STV) remanescente no substrato (55\%) ao final do período, indicando que a produção de biogás ainda aumentaria, embora em menor taxa diária.

As curvas de produção acumulada de biogás apresentadas por Parawira et al. (2004), que investigaram a biodegradação anaeróbia de resíduos de batata e codigerida com folhas de beterraba, e por Schirmer et al. (2014), apresentaram padrão semelhante e a mesma tendência observada neste estudo.

A Tabela 2 mostra os resultados quantitativos de geração de biogás nos biodigestores ao longo dos 91 dias de monitoramento.

Tabela 2. Produção de biogás após 91 dias

\begin{tabular}{|c|c|c|c|c|c|}
\hline है: & $\begin{array}{l}\text { Geração média } \\
\text { bruta acumulada } \\
\text { de biogás (mL) }\end{array}$ & $\begin{array}{l}\text { Geração } \\
\text { média líquida } \\
\text { acumulada de } \\
\text { biogás (mL) }\end{array}$ & $\begin{array}{l}\text { Geração média } \\
\text { líquida por SV } \\
\text { adicionado } \\
\left(\mathrm{mL} \cdot \mathrm{g}_{\mathrm{sv}}^{-1} \text { adicionado }\right)\end{array}$ & $\begin{array}{l}\text { Geração média } \\
\text { líquida por SV } \\
\text { degradado (mL. } \\
\left.\mathrm{g}_{\mathrm{sV} \text { degradado }}{ }^{-1}\right)\end{array}$ & $\begin{array}{l}\text { Geração média } \\
\text { líquida por grama } \\
\text { de resíduo seco } \\
\left(\mathrm{mL}_{\text {resíduoseco }}{ }^{-1}\right)\end{array}$ \\
\hline I & $236,70 \pm 71,18$ & - & - & - & - \\
\hline$S$ & $429,97 \pm 27,64$ & $193,27 \pm 12,78$ & $122,66 \pm 20,04$ & $235,90 \pm 13,34$ & $96,64 \pm 18,89$ \\
\hline
\end{tabular}

A Tabela 2 traz uma produção líquida média de 193,27 mL de biogás, que corresponde à efetiva geração de biogás pelo resíduo sólido orgânico fresco. Em termos de resíduo adicionado, a geração líquida de biogás foi de $96,64 \mathrm{~mL} \cdot \mathrm{g}_{\text {resíduo }}$ ${ }_{\text {seco }}^{-1}$ (ou 96,64 $\mathrm{m}^{3} \cdot \mathrm{t}_{\text {resíduo seco }}^{-1}$ ), o que corresponde ao potencial de geraçãa de biogás (do qual uma parte consiste no $L_{0}$ obtido experimentalmente). Comparativamente a outros estudos, essa geração de biogás pode ser considerada baixa (considerando 
ainda que os resultados foram expressos em termos de biogás e não apenas metano, cuja conversão reduz ainda mais o valor obtido, para cerca de 50 a 60\%). A produção observada por Hansen et al. (2004) foi de $495 \mathrm{~mL}_{\mathrm{CH} 4} \mathrm{~g}_{\mathrm{Sv}}{ }^{-1}$.

Com a digestão anaeróbia de resíduos de batata, Parawira et al. (2004) obtiveram uma produção de metano máxima de $0,32 \mathrm{L.g}_{\text {Svdegradado }}{ }^{-1}$, a $40 \%$ de ST, razão inóculo-substrato de 1,5, resultado também superior ao deste trabalho.

Em estudo semelhante com resíduos frescos (novos) do Aterro da Muribeca (Pernambuco) inoculados com lodo, Schirmer et al. (2014) reportam produção de biogás de $1816 \mathrm{NmL}$ ou $75 \mathrm{NmL} . \mathrm{g}_{\mathrm{sv}}{ }^{-1}$ para resíduos frescos; portanto, abaixo daquela observada neste estudo.

O potencial de geração de biogás, obtido por Maciel (2009) em seu ensaio BMP com resíduo in natura, variou de 124,0 a 189,6 NmL, o que equivale a 381,5 a $462,4 \mathrm{NmL} . \mathrm{g}_{\mathrm{sv}}{ }^{-1}$. Em termos de matéria seca, o potencial de biogás (BGP) variou de 112,7 a 172,4 NmL. ${ }_{\text {seca }}{ }^{-1}$ (MACIEL, 2009; MACIEL; JUCÁ, 2011), sendo que o valor inferior fica próximo do encontrado neste estudo, de $96,64 \mathrm{~mL}_{\text {biogás }} \cdot \mathrm{g}_{\text {resíduo seco }}{ }^{-1}$.

Assim, fica evidente que as comparações entre a produção de metano (ou biogás) dos estudos encontrados na literatura são dificultosas, o que se deve às diferenças nos experimentos, que vão desde o tipo de resíduo e inóculo utilizados, até as diferentes condições operacionais que são empregadas (PARAWIRA et al., 2004).

\subsection{MODELAGEM DO POTENCIAL DE GERAÇÃO DE BIOGÁS}

\subsubsection{Abordagem prática}

a) Cálculo das varáveis k e $\mathrm{L}_{0}$ (obtidas experimentalmente): O valor de $L_{0}$ foi obtido por meio dos ensaios com o resíduo fresco, cuja produção máxima de biogás foi igual a 193,27 mL. Em termos de resíduo adicionado, a geração de biogás foi de $96,64 \mathrm{~mL} \cdot \mathrm{g}_{\text {resíduo seco }}{ }^{-1}$ (ou $96,64 \mathrm{~m}^{3} \cdot \mathrm{t}_{\text {resíduo seco }}{ }^{-1}$ ), o que corresponde ao potencial de geração de biogás. Para o cálculo do potencial de geração de metano foi aplicado um percentual de $50 \%$, resultando em um $L_{0}$ obtido experimentalmente igual a $48,32 \mathrm{~m}^{3} \cdot \mathrm{t}_{\text {residuo }}$ ${ }_{\text {seco }}^{-1}$. Diante do resultado de não geração de biogás no primeiro dia de incubação e pelo aspecto da amostra no momento da coleta, que já estava em estágio avançado de degradação, inferiu-se que a parcela facilmente 
biodegradável já fora praticamente consumida dentro da célula do aterro. Assim, determinou-se um valor de $t$ (tempo) para degradação dos resíduos orgânicos igual a 2,5 anos, fornecendo um $k$ igual a 0,4 ano $^{-1}$, uma vez que $k=\mathrm{t}^{-1}$.

b) Operacionalização do modelo LandGEM (variáveis experimentais): O resultado obtido com a operacionalização do modelo LandGEM, utilizando a abordagem prática, ou seja, fazendo uso das variáveis calculadas experimentalmente, pode ser visto na Figura 3.

Emissões de Biogás, $\mathrm{CH}_{4}, \mathrm{CO}_{2}$ e NMOC (t/ano)

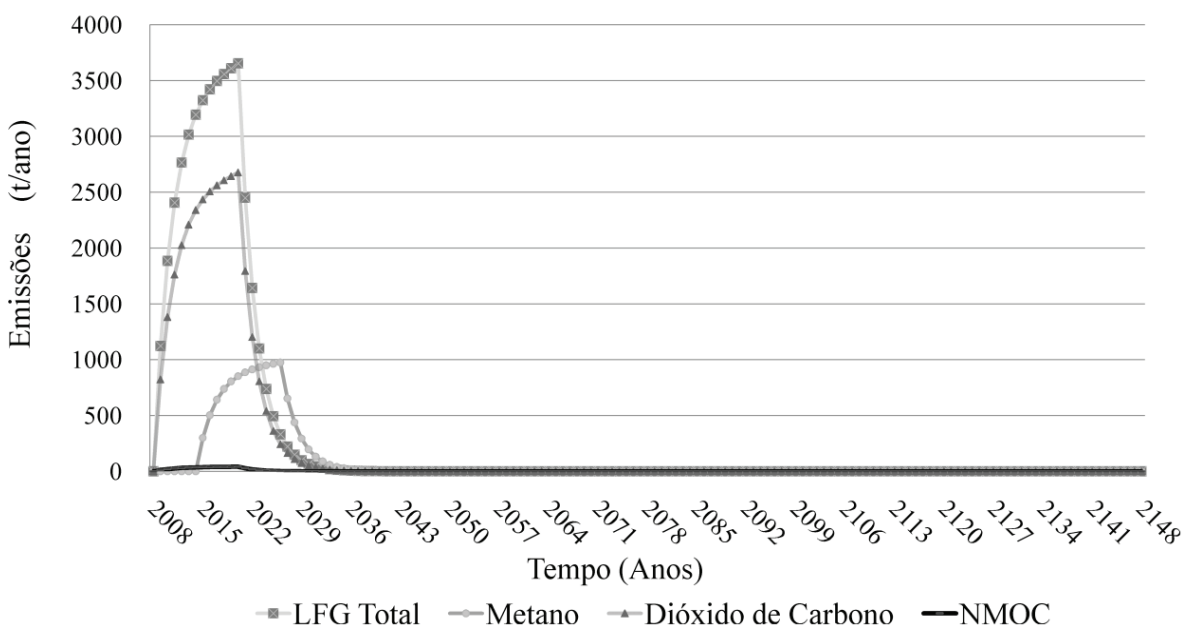

Figura 3. Resultados obtidos com o LandGEM: abordagem prática

Observa-se que o maior ritmo de produção de biogás se dá nos primeiros 20 anos, até 2028 , ano em que a geração seria de aproximadamente $150 \mathrm{t}_{\text {biogás }}$. ano $^{-1}$. Esta rápida geração se deve ao fato de que as variáveis $k$ e $L_{0}$ foram calculadas com base nas características dos resíduos orgânicos, os quais possuem um tempo menor de degradação do que os materiais recicláveis. Em 2052, já pode ser considerada finalizada a geração de biogás, pois volumetricamente a mesma já estaria bastante reduzida. O pico da geração de biogás ocorreria, segundo esta estimativa, no ano 2020, a uma taxa de 3.654 t.ano ${ }^{-1}$ de biogás e 976 t.ano ${ }^{-1}$ de metano. O total de biogás acumulado de 2008 a 2148, de acordo com a estimativa utilizando a abordagem 
prática, seria de aproximadamente 42.877 t de biogás e 11.453 t de metano.

\subsubsection{Abordagem teórica}

a) Seleção das variáveis $k$ e $L_{0}$ (default): Foram selecionados como inputs para a operacionalização da abordagem teórica do LandGEM um valor padrão de $k$ igual a 0,05 ano $^{-1}$; e para $L_{0}$ o valor de $170 \mathrm{~m}^{3} \cdot \mathrm{t}_{\mathrm{RSU}}{ }^{-1}$ (USEPA, 2005).

b) Operacionalização do modelo LandGEM (com as variáveis default): O resultado da operacionalização do modelo LandGEM, utilizando a abordagem teórica (com variáveis default), pode ser observado na Figura 4 .

Emissões de Biogás, $\mathrm{CH}_{4}, \mathrm{CO}_{2}$ e NMOC (t/ano)

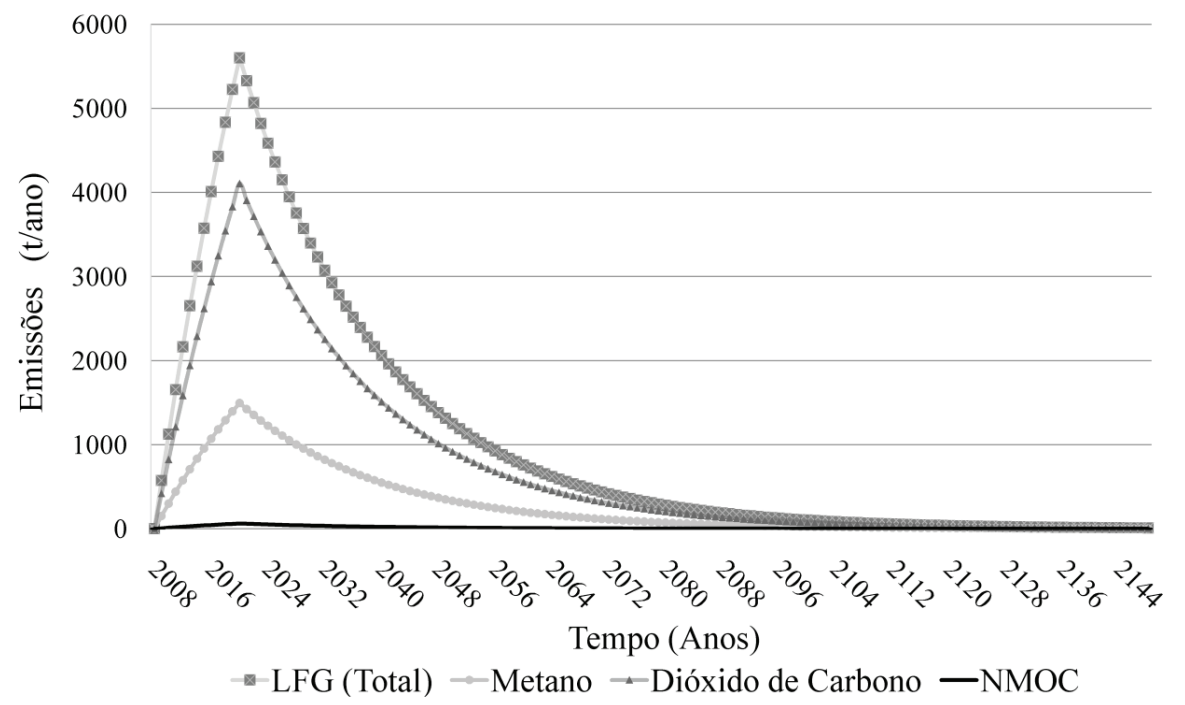

Figura 4. Resultados obtidos com o LandGEM: abordagem teórica

É possível identificar as maiores taxas de produção de biogás nos primeiros 70 anos, até 2078, ano em que a geração seria de aproximadamente 300 t.ano $^{-1}$. O pico da geração de biogás ocorreria, da mesma forma que na abordagem prática, 
no ano de 2020, a uma taxa de 5.602 t.ano $^{-1}$ de biogás e 1.496 t.ano ${ }^{-1}$ de metano. Essas proporções convergem com a literatura, já que os gases predominantes na composição do biogás são o metano e o dióxido de carbono (IMRE et al., 2009; MAGHANAKI et al., 2013). O total de biogás acumulado de 2008 a 2148, de acordo com a estimativa utilizando a abordagem teórica, seria de aproximadamente 148.062 t de biogás e 39.549 t de metano.

\subsubsection{Análise comparativa das curvas de geração: abordagem prática $\mathbf{x}$ abor- dagem teórica}

Na Tabela 3 é apresentado um resumo dos resultados obtidos com as duas abordagens de previsão de geração de biogás por meio do LandGEM.

Tabela 3. Comparação entre as abordagens prática e teórica (resumo)

\begin{tabular}{|c|c|c|c|c|c|c|c|c|c|c|c|}
\hline \multirow{2}{*}{ 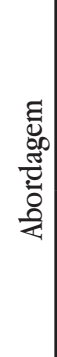 } & \multirow{2}{*}{ 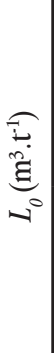 } & \multirow{2}{*}{ 店 } & \multicolumn{5}{|c|}{ Pico da geração de biogás } & \multicolumn{2}{|c|}{$\begin{array}{l}\text { Final da geração o } \\
\text { de biogás }\end{array}$} & \multicolumn{2}{|c|}{$\begin{array}{c}\text { Total acumulado } \\
\text { no período (2008 } \\
\text { a 2148) }\end{array}$} \\
\hline & & & Ano & $\begin{array}{l}\text { Total de } \\
\text { biogás } \\
\left(\text { t.ano }^{-1}\right)\end{array}$ & $\begin{array}{c}\mathrm{CH}_{4} \\
\left(\operatorname{ttano}^{-1}\right)\end{array}$ & $\begin{array}{c}\mathrm{CO}_{2} \\
\left(\mathrm{t}^{-a n 0^{-1}}\right)\end{array}$ & $\begin{array}{l}\text { NMOC } \\
\left(\text { t.ano }^{-1}\right)\end{array}$ & Ano & $\begin{array}{l}\text { Total de } \\
\text { biogás } \\
\left(\text { t.ano }{ }^{-1}\right)\end{array}$ & $\begin{array}{l}\text { Total de } \\
\text { biogás } \\
(\mathrm{t})\end{array}$ & $\begin{array}{c}\mathrm{CH}_{4} \\
(\mathrm{t})\end{array}$ \\
\hline : & $\begin{array}{l}\tilde{a} \\
\substack{\infty \\
+}\end{array}$ & $\stackrel{t}{0}$ & 2020 & 3.654 & 976 & 2.678 & 42 & 2.052 & 0,01 & 42.877 & 11.453 \\
\hline 플. & $\stackrel{R}{I}$ & $\stackrel{1}{0}$ & 2020 & 5.602 & 1.496 & 4.106 & 64 & 2.148 & 9,31 & 148.062 & 39.549 \\
\hline
\end{tabular}

Nas duas abordagens, o pico na taxa de produção de biogás ocorre no mesmo ano, em 2020. Ou seja, o que determinou o maior volume de produção, neste caso, é principalmente a quantidade de lixo aterrada. Assim, verifica-se que a maior taxa de geração de biogás (em t.ano ${ }^{-1}$ ) ocorrerá, muito provavelmente, quando 
o máximo de resíduos estiver disposto no aterro, ao final da sua vida útil.

Já os períodos de distribuição das maiores taxas de geração de biogás diferiram bastante entre uma abordagem e outra, já que na abordagem prática 0 maior ritmo de produção ocorre em aproximadamente 20 anos, e na abordagem teórica esse período se estende por cerca de 70 anos. Isso ocorre porque as variáveis que determinam a cinética da degradação foram calculadas, na abordagem prática, segundo os resultados do ensaio dos biodigestores de bancada, ou seja, utilizando como referência apenas resíduos orgânicos, os quais possuem um tempo menor de degradação do que a massa contendo orgânicos e recicláveis. Fica clara a diferença do tempo previsto de degradação pelos valores adotados como $k$, pois enquanto na abordagem prática o $k$ foi igual a $0,4 \mathrm{ano}^{-1}$, na abordagem teórica o $k$ foi igual a $0,05 \mathrm{ano}^{-1}$, ou seja, o $k$ calculado era oito vezes maior que o default. Isso resulta em duas curvas distintas (uma degradação muito mais rápida que a outra), indicando que a viabilidade econômica da atividade de recuperação energética do biogás pode compreender um período bem mais curto do que a teoria pressupõe.

Firmo (2013) aponta que nas estimativas de geração de biogás no Brasil é possível utilizar dados default, construindo, assim, um cenário conservador. Por outro lado, a mesma autora destaca que é possível duplicar ou aumentar ainda mais a constante cinética da degradação para que se tenha um cenário mais otimista. Esse procedimento reflete o adotado neste estudo, em que o valor prático da variável $k$ foi muito superior ao valor default.

No ano de pico da taxa de geração na abordagem prática o volume gerado seria menor do que previsto teoricamente e, em termos de valores acumulados ao longo de todo o tempo, a abordagem prática apresenta um volume de aproximadamente $29 \%$ do volume total teórico. Essa diferença na geração acumulada já era esperada, pois o parâmetro $L_{0}$ da abordagem prática (igual a 48,32 $\mathrm{m}^{3} \cdot \mathrm{t}_{\text {resíduo }}{ }^{-1}$ ) foi bem menor do que o valor default adotado na abordagem teórica (de $\left.170 \mathrm{~m}^{3} \cdot \mathrm{t}_{\mathrm{RSU}}^{-1}\right)$, valores estes que relacionam uma quantidade a ser gerada de biogás com o volume de resíduo aterrado. Como a quantidade de resíduo era a mesma em ambas as abordagens, a diferença pode ser atribuída ao valor de $L_{0}$, então na abordagem prática seria gerado menos biogás por tonelada de resíduo.

Como cada aterro se constitui em um ecossistema único, comparações 
diretas entre estudos que abordam estimativas de geração de biogás a partir de resíduos sólidos podem ser difíceis, o que reforça a importância do estudo individualizado do comportamento de cada aterro. Logo, o desafio atual na modelagem da geração de biogás é conseguir representar essa heterogeneidade e diferentes condições locais, e adequar cada realidade a modelos comercialmente disponíveis ou que apresentem com menor erro o comportamento hidráulico, térmico, mecânico e bioquímico do sistema. E é neste aspecto que os estudos experimentais e de aterros podem servir como subsídio aos valores dos parâmetros de entrada nos modelos, de forma que se tenha uma base de dados brasileira, mais adequada a essa realidade específica, e que permita uma análise crítica dos valores default reportados pela literatura (FIRMO, 2013).

\section{CONSIDERAÇÕES FINAIS}

Os ensaios com os biodigestores de bancada se mostraram uma alternativa viável ao estudo da biodegradação de resíduos sólidos. Isso se deve ao baixo custo e simplicidade operacional, quando são comparados aos estudos de campo, que são mais dispendiosos e de maior complexidade.

Com o estudo experimental foi possível obter alguns dos parâmetros de entrada necessários à modelagem do potencial de geração de biogás, utilizando o modelo de primeira ordem LandGEM. A comparação dos resultados das abordagens prática e teórica mostra que teoricamente a geração acumulada de biogás poderia ser quase três vezes maior do que na prática, levando-se em conta a natureza essencialmente orgânica dos resíduos trabalhados bem como as condições padronizadas de degradação do resíduo, controle e monitoramento do processo nos ensaios de bancada. Cabe salientar que os valores padrão (utilizados na abordagem teórica) podem conduzir a erros também, pois não são exatos e específicos para os diferentes locais de aplicação (cada país ou região apresenta fatores diversos que interferem na dinâmica da biodegradação e na emissão de gases).

O estudo da quantidade de biogás a ser produzida ao longo da vida útil de um aterro e após seu encerramento traz informações importantes à adequada 
e eficiente gestão de um aterro sanitário. Conhecer a provável curva de geração de biogás pelos resíduos sólidos confinados é um fator primordial ao estudo da viabilidade técnica e econômica da venda da energia do biogás, pois norteia o cálculo da provável receita a ser obtida com a recuperação energética das emissões gasosas, bem como o custo do sistema necessário para a coleta e aproveitamento, que depende diretamente da quantidade e características do biogás gerado. Além desses benefícios, as estimativas de produção e recuperação do gás do lixo possibilitam a construção de um panorama acerca da redução de emissões e projetos do mecanismo de desenvolvimento limpo, medidas que podem transformar um aterro sanitário em um negócio rentável e ambientalmente adequado.

\section{AGRADECIMENTOS}

Os autores agradecem às seguintes agências brasileiras de fomento pelo suporte financeiro: Fundação Araucária do Paraná; Secretaria de Estado da Ciência, Tecnologia e Ensino Superior do Paraná (Seti).

\section{REFERÊNCIAS}

ASSOCIAÇÃO BRASILEIRA DE NORMAS TÉCNICAS. NBR 10007: Amostragem de resíduos sólidos. Rio de Janeiro: ABNT, 2004. 21p.

ASSOCIAÇÃO BRASILEIRA DE EMPRESAS DE LIMPEZA PÚBLICA E RESÍDUOS ESPECIAIS - ABRELPE. Mgm Innova. Atlas brasileiro de emissões de GEE e potencial energético na destinação de resíduos sólidos. São Paulo: ABRELPE, 2013.

ALCÂNTARA, P. B. Avaliação da influência da composição de resíduos sólidos urbanos no comportamento de aterros simulados. Tese (Doutorado em Engenharia Civil) - Programa de Pós-graduação em Engenharia Civil, Universidade Federal de Pernambuco, Recife, 2007.

ALKANOK, G.; DEMIREL, B.; ONAY, T. T. Determination of biogas generation potential 
as a renewable energy source from supermarket wastes. Waste Management, v. 34, n. 1, p.134-140, 2014.

ANDREOLI, C. V.; FERREIRA, A. C.; CHERNICHARO, C. A.; BORGES, E. S. M. Secagem e higienização de lodos com aproveitamento de biogás. In: CASSINI, S. T. (Ed.). Digestão de resíduos sólidos orgânicos e aproveitamento do biogás. Rio de Janeiro: ABES, Rima, 2003. p. 121-165.

ANGELIDAKI, I.; ALVES, M.; BOLZONELLA, D.; BORZACCONI, L.; CAMPOS, J. L.; GUWY, A. J.; KALYUZHNYI, S.; JENICEK, P.; VAN LIER, J. B. Defining the biomethane potential (BMP) of solid organic wastes and energy crops: a proposed protocol for batch assays. Water Science \& Technolog y, v. 59, n. 5, p. 927-934, 2009.

AMERICAN PUBLIC HEALTH ASSOCIATION - APHA. Standard Methods for the Examination of Water and Wastewater. American Public Health Association, American Water Works Association, Water Environmental Federation, 20. ed. Washington, 1998.

BANCO MUNDIAL. Manual para a Preparação de Gás de Aterro Sanitário para Projetos de Energia na América Latina e Caribe. Disponível em: < http://www. worldbank.org >. Acesso em: 22 jun. 2015.

BIDONE, F. R. A; POVINELLI, J. Conceitos básicos de resíduos sólidos. São Carlos: EESC/USP, 1999. 109p.

BRASIL. Lei Federal $n^{0} 12.305$, de 02 de agosto de 2010. Institui a Política Nacional de Resíduos Sólidos; altera a Lei no 9.605, de 12 de fevereiro de 1998; e dá outras providências. Brasília, 2010. Disponível em: < http://www.planalto.gov.br/ ccivil_03/_ato2007-2010/2010/lei/112305.htm>. Acesso em: 22 jun. 2015.

CHERNICHARO, C. A. L. Reatores anaeróbios. 2. ed. Belo Horizonte: Ed. UFMG, 1997. 380p. (Princípios do Tratamento Biológico de Águas Residuárias, v. 5).

DECOTTIGNIES, V.; GALTIER, L.; LEFEBVRE, X.; VILLERIO, T. Comparison of analytical methods to determine the stability of municipal solid waste and related 
wastes. In: PROCEEDINGS SARDINIA, Tenth International Waste Management and Landfill Symposium, S. Margherita di Pula, Cagliari, Italy, 2005.

FIRMO, A. L. B. Estudo numérico e experimental da geração de biogás a partir da biodegradação de resíduos sólidos urbanos. Tese (Doutorado em Engenharia Civil) - Programa de Pós-graduação em Engenharia Civil, Universidade Federal de Pernambuco, Recife, 2013.

HANSEN, T. L.; SCHMIDT, J. E.; ANGELIDAKI, I.; MARCA, E.; JANSEN, J. L. C.; MOSB/EK H.; CHRISTENSEN, T. H. Method for determination of methane potentials of solid organic waste. Waste Management, v. 24, n. 4, p.393-400, 2004.

INSTITUTO AGRONÔMICO DO PARANÁ - IAPAR. Cartas climáticas do Paraná. IAPAR, 1998. Disponível em: <http://www.iapar.br/modules/conteudo/conteudo. php?conteudo=863>. Acesso em 27 fev. 2014.

INSTITUTO BRASILEIRO DE GEOGRAFIA E ESTATÍSTICA - IBGE. Taxa média geométrica de crescimento anual da população (população presente e residente) - grandes regióes - sul. IBGE, 2010. Disponível em: <http:// seriesestatisticas.ibge.gov.br/series.aspx?vcodigo=pop119>. Acesso em: 05 maio 2014.

IMRE, E.; KOVÁCS, K. L.; BAGI, Z.; ÁCS, N.; PEREI, R. K.; BARTHA, I.; TRANG P. Q.; TELEKES, G. Biotechnological methods to increase landfill gas production. In: PROCEEDINGS SARDINIA, Twelfth International Waste Management and Landfill Symposium, S. Margherita di Pula, Cagliari, Italy, 2009.

KELLY, R. J. Solid waste biodegradation enhancements and the evaluation of analytical methods used to predict waste stability. Master Thesis (Master of Science in Environmental Science and Engineering) - Faculty of Virginia Polytechnic Institute and State University, Blacksburg (Virginia), 2002.

LABATUT, R. A.; ANGENENT, L. T.; SCOTT, N. R. Biochemical methane potential and biodegradability of complex organic substrates, Bioresource Technology, v. 102, n. 3, p. 2255-2264, 2011. 
MACIEL, F. J. Geração de biogás e energia em aterro experimental de resíduos sólidos urbanos. Tese (Doutorado em Engenharia Civil) - Programa de Pósgraduação em Engenharia Civil, Universidade Federal de Pernambuco, Recife, 2009.

MACIEL, F. J., JUCÁ, J. F. T. Evaluation of landfill gas production and emissions in a MSW large-scale experimental cell in Brazil. Waste Management, v. 31, n. 5, p.966977, 2011.

MAGHANAKI, M. M.; GHOBADIAN, B.; NAJAFI, G.; GALOGAH, R. J. Potential of biogas production in Iran. Renewable and Sustainable Energy Reviews, v. 28, p.702-714, 2013.

MSHANDETE, A.; KIVAISI, A.; RUBINDAMAYUGI, M.; MATTIASSON, B. Anaerobic batch co-digestion of sisal pulp and fish wastes. Bioresource Technology, v. 95, n. 1, p.19-24, 2004.

PARAWIRA, W.; MURTO, M.; ZVAUYA, R.; MATTIASSON, B. Anaerobic batch digestion of solid potato waste alone and in combination with sugar beet leaves. Renewable Energy, v. 29, n. 11, p. 1811-1823, 2004.

PIVELI, R. P.; KATO, M. T. Qualidade das águas e poluição: aspectos físico-químicos. São Paulo: ABES, 2005. 285p.

RASI, S.; LÄNTEL̈̈. J.; RINTALA, J. Trace compounds affecting biogas energy utilisation - a review. Energ y Conversion and Management, v.52, n.12, p.3369-3375, 2011.

SCHIRMER, W. N.; JUCÁ, J. F. T.; SCHULER, A. R. P.; HOLANDA, S.; JESUS, L. L. Methane production in anaerobic digestion of organic waste from Recife (Brazil) Landfill: evaluation in refuse of different ages. Brazilian Journal of Chemical Engineering, v. 31, n. 2, p. 373-384, 2014.

STAUB, M. J. et al. An incremental model to assess the environmental impact of cap cover systems on MSW landfill emissions. Geotextiles and Geomembranes, v. 29, n. 3, p. 298-312, 2011. 
UNITED STATES ENVIRONMENTAL PROTECTION AGENCY - USEPA. Air emissions from municipal solid waste landfills: background information for proposed standards and guidelines. [s.1.]: Emission Standards Division.EPA-450/3-90-011a, 1991.

UNITED STATES ENVIRONMENTAL PROTECTION AGENCY - USEPA. Landfill Gas Emissions Model (LandGEM): version 3.02 - user's guide. EPA-600/R-05/047, 2005.

VOGT, W. G.; AUGENSTEIN, D. Final report: comparison of models for predicting landfill methane recovery. SCS Engineers and Institute for Environmental Management (IEM). 1997. 102p.

VON SPERLING, M. Princípios básicos do tratamento de esgotos. Belo Horizonte: Ed. da UFMG, 1996. 211 p. (Princípios do Tratamento Biológico de Águas Residuárias, v. 2).

VON SPERLING, M. Introdução à qualidade das águas e ao tratamento de esgotos. 3. ed. Belo Horizonte: Ed. UFMG, 2005. 452p. (Princípios do Tratamento Biológico de Águas Residuárias, v. 1).

ZHANG, P.; ZENG, G.; ZHANG, G.; LI, Y.; ZHANG, B.; FAN, M. Anaerobic co-digestion of biosolids and organic fraction of municipal solid waste by sequencing batch process. Fuel Processing Technology, v. 89, n. 4, p. 485-489, 2008.

Recebido em: 2015-12-16 Aceito em: 2017-03-02 